\title{
EULAR revised recommendations for the management of fibromyalgia
}

\author{
G J Macfarlane, ${ }^{1}$ C Kronisch, ${ }^{1,2}$ L E Dean, ${ }_{1}^{1}$ F Atzeni, ${ }^{3}$ W Häuser, ${ }^{4,5}$ E Fluß, ${ }^{1}$ E Choy, ${ }^{6}$ \\ E Kosek, ${ }^{7} \mathrm{~K}$ Amris, ${ }^{8}$ J Branco, ${ }^{9} \mathrm{~F}$ Dincer ${ }_{10}{ }^{10} \mathrm{P}$ Leino-Arjas, ${ }_{1}{ }^{11} \mathrm{~K}$ Longley, ${ }^{12}$ \\ G M McCarthy, ${ }^{13}$ S Makri, $^{14}$ S Perrot $_{,}{ }^{15}$ P Sarzi-Puttini, $^{16}$ A Taylor, $^{17}{ }^{17}$ T Jones ${ }^{1}$
}

Handling editor Tore K Kvien

- Additional material is published online only. To view please visit the journal online (http://dx.doi.org/10.1136/ annrheumdis-2016-209724).

For numbered affiliations see end of article.

\section{Correspondence to} Professor G J Macfarlane, Epidemiology Group, University of Aberdeen, School of Medicine, Medical Sciences and Nutrition, Polwarth Building, Foresterhill, Aberdeen, Scotland AB25 2ZD UK; g.j.macfarlane@abdn.ac.uk

Received 15 April 2016 Revised 10 June 2016

Accepted 14 June 2016 Published Online First 4 July 2016

CrossMark

To cite: Macfarlane GJ, Kronisch C, Dean LE, et al. Ann Rheum Dis

2017:76:318-328.

\section{ABSTRACT}

Objective The original European League Against

Rheumatism recommendations for managing fibromyalgia assessed evidence up to 2005. The paucity of studies meant that most recommendations were 'expert opinion'.

Methods A multidisciplinary group from 12 countries assessed evidence with a focus on systematic reviews and meta-analyses concerned with pharmacological/nonpharmacological management for fibromyalgia. A review, in May 2015, identified eligible publications and key outcomes assessed were pain, fatigue, sleep and daily functioning. The Grading of Recommendations Assessment, Development and Evaluation system was used for making recommendations.

Results 2979 titles were identified: from these 275 full papers were selected for review and 107 reviews (and/or meta-analyses) evaluated as eligible. Based on metaanalyses, the only 'strong for' therapy-based recommendation in the guidelines was exercise. Based on expert opinion, a graduated approach, the following four main stages are suggested underpinned by shared decision-making with patients. Initial management should involve patient education and focus on nonpharmacological therapies. In case of non-response, further therapies (all of which were evaluated as 'weak for' based on meta-analyses) should be tailored to the specific needs of the individual and may involve psychological therapies (for mood disorders and unhelpful coping strategies), pharmacotherapy (for severe pain or sleep disturbance) and/or a multimodal rehabilitation programme (for severe disability).

Conclusions These recommendations are underpinned by high-quality reviews and meta-analyses. The size of effect for most treatments is relatively modest. We propose research priorities clarifying who will benefit from specific interventions, their effect in combination and organisation of healthcare systems to optimise outcome.

\section{INTRODUCTION}

Fibromyalgia is common with a prevalence of $2 \%$ in the general population. ${ }^{1}{ }^{2}$ However, its diagnosis and management remain a challenge for patients and healthcare professionals. It often takes $>2$ years for a diagnosis to be made with an average of 3.7 consultations with different physicians. ${ }^{3}$ Referral to specialists and investigations results in high healthcare use, for up to 10 years prior to diagnosis, compared with persons who do not have fibromyalgia. ${ }^{4}$
Although pain is the dominant symptom in fibromyalgia, other symptoms such as fatigue, nonrefreshed sleep, mood disturbance and cognitive impairment are common, but not universal, have an important influence on quality of life and emphasise that it is a heterogeneous and complex condition. ${ }^{5} 6$

The original European League Against Rheumatism (EULAR) recommendations for the management of fibromyalgia assessed evidence up to and including 2005. ${ }^{7}$ Given the paucity of information and poor quality of the studies available, it was recommended that the guidelines be revised after a period of 4 years. However, no subsequent revision took place and thus a decade later we revisit the recommendations with the aim of making them more evidence based. In the time since the original recommendations, there have been a considerable number of individual trials examining pharmacological and non-pharmacological interventions and, moreover, there have been systematic reviews conducted for nearly all of the commonly used management strategies. Our aim therefore was, using the systematic reviews conducted and taking into account their quality, to make evidence-based recommendations for the use of individual pharmacological and non-pharmacological approaches, and how these could be combined. Further, we aimed to identify priority areas for future research.

\section{METHODS}

\section{Working group membership}

The working group included 18 members from 12 European countries: clinicians (representing rheumatology, internal medicine, pain medicine and epidemiology), non-clinical scientists (occupational health, epidemiology), patient representatives and the allied health professions (nursing).

\section{Eligibility, search strategy and quality assessment}

We focused on systematic reviews (with or without meta-analysis) concerned with the management of fibromyalgia. Details of eligibility, review and quality assessment are provided in online supplementary text.

\section{Evaluating evidence}

We retained pain as one of the key outcomes of interest, from the original guidelines, but also included fatigue, sleep and daily functioning. The committee considered the following in making a 
recommendation: number of trials, number of patients, outcomes assessed, quality of reviews and the trials included within the reviews, effect size (and 95\% CI), adverse events and cost. We used the Grading of Recommendations Assessment, Development and Evaluation system for making recommendations. ${ }^{10}$ This is a four-point scale: strong for/weak for/weak against/strong against; or allowing a recommendation 'use only for research'. The strength of recommendation is based on the balance between desirable and undesirable effects (considering values and preferences), confidence in the magnitude of effects and resource use. A strong recommendation implies that, if presented with the evidence, all or almost all informed persons would make the recommendation for or against the therapy, while a weak recommendation would imply that most people would, although a substantial minority would not. ${ }^{11}$

Two subgroups considered the evidence for pharmacological and non-pharmacological therapies and proposed a recommendation. At a face-to-face meeting, after presentation of the evidence and the preliminary recommendation, discussion resulted in a 'final recommendation'. In addition to the evidence on efficacy/effectiveness, the committee also took into account safety. All participants then voted on their level of agreement with the recommendation on a scale from 0 , 'completely disagree', to 10 , 'completely agree'. The percentage of the committee scoring at least 7 was taken to indicate level of agreement.

\section{RESULTS}

In total, 2979 titles were identified. From these, 571 abstracts and then 275 full papers were selected for review, and 107 reviews evaluated as eligible for consideration in making recommendations for management (figure 1).

Information on the reviews informing these recommendations on pharmacological therapy and on non-pharmacological and complementary and alternative medicines/therapies is collated in online supplementary tables A and B, respectively, while information from one review, for each medicine/therapy, selected based on recency and quality is provided in tables 1 and 2, respectively.

\section{Evaluation of pharmacological medicines Amitriptyline}

Five reviews included up to 13 trials and a maximum of 919 subjects. Häuser et $a l^{12}$ reported that patients receiving amitriptyline were more likely to achieve $30 \%$ pain reduction (risk ratio (RR) $1.60,95 \% \mathrm{CI} 1.15$ to 2.24 ), equivalent to a 'number needed to treat' (NNT) of $3.54,95 \%$ CI 2.74 to 5.01. There was a moderate effect on sleep (standardised mean difference (SMD) $-0.56,95 \% \mathrm{CI}-0.78$, to -0.34$)^{\mathrm{i}}$ and small effect on fatigue $(-0.44 ;-0.71$ to -0.16$)$. There was no difference in discontinuation rates compared with patients receiving placebo. Nishishinya et $a l^{13}$ in their high-quality review concluded that $25 \mathrm{mg} /$ day improved pain, sleep and fatigue at 6-8 weeks of treatment but not at 12 weeks while $50 \mathrm{mg} /$ day did not demonstrate efficacy. Amitriptyline evaluation: weak for, at low dose (100\% agreement).

\section{Anticonvulsants}

Nine reviews of pregabalin included up to seven studies and a maximum of 3344 patients. A recent Cochrane review ${ }^{24}$ reported patients receiving active treatment were more likely to

${ }^{\mathrm{i}}$ All effect sizes are expressed as SMD with 95\% CI unless otherwise stated. have $30 \%$ pain reduction, RR 1.37 , 95\% CI 1.22 to 1.53 , with a 'number needed to benefit' (NNTB) over placebo of $9,95 \%$ CI 7 to 13 . There was a very small effect on fatigue $(-0.17$; -0.25 to -0.09$)$ and small effect on sleep $(-0.35 ;-0.43$ to $-0.27)$ but no effect on disability $(-0.01 ;-0.11$ to 0.09$)$. A single, moderate quality, study of gabapentin in 150 subjects (eg, in ref. 104) showed a significant effect on 30\% pain reduction (RR 1.65 , 95\% CI 1.10 to 2.48 ), a small effect on sleep $(-0.71 ;-1.08$ to -0.24$)$ and a large effect on disability $(-0.94$; -1.32 to -0.56). Anticonvulsant evaluation: pregabalin-weak for (94\% agreement); gabapentin-research only (100\% agreement).

\section{Cyclobenzaprine}

A single systematic review of five studies involving 312 patients reported that of those taking cyclobenzaprine $85 \%$ experienced side effects and only $71 \%$ completed the studies. They were more likely to report themselves as 'improved' (NNT 4.8, 95\% CI 3.0 to 11.0$)$. Only two studies reported an intentionto-treat' (ITT) analysis. Sleep, but not pain, showed a significant, very small, improvement relative to baseline at the longest outcome considered (12 weeks: SMD 0.34) and patients on placebo showed similar improvement (SMD 0.52). ${ }^{25}$ Cyclobenzaprine evaluation: weak for (75\% agreement).

\section{Growth hormone}

A single systematic review of two studies involving 74 patients reported an effect size on pain of 1.36 (0.01 to 1.34$).{ }^{16}$ The improvement in functional deficit was not statistically significant (1.24; -0.36 to 2.84$)$. There are concerns on safety (sleep apnoea, carpal tunnel syndrome). The drug is not approved for fibromyalgia (FM) or related disorders in Europe. Growth hormone evaluation: strong against (94\% agreement).

\section{Monoamine oxidase inhibitors}

Four reviews identified up to three studies and 241 patients. Häuser $e t a l^{26}$ reported a moderate effect on pain across the studies $(-0.54 ;-1.02$, to -0.07$)$, but the single studies that evaluated fatigue and sleep showed no effect. There were no differences in dropouts or adverse events compared with placebo. There was no comparison between compounds. Life-threatening interactions have been documented. Monoamine oxidase inhibitors (MAOIs) evaluation: weak against (81\% agreement).

\section{NSAIDs}

A single review ${ }^{21}$ identified two small trials with no evidence of improved outcome compared with placebo. One low-quality review was not considered. Non-steroidal anti-inflammatory drugs (NSAIDs) evaluation: weak against (100\% agreement).

\section{Serotonin-noradrenalin reuptake inhibitors}

Eight systematic reviews were identified, which presented data separately for duloxetine. The largest review of 2249 subjects $^{32}$ reported duloxetine, short term (up to 12 weeks) and long term (up to 28 weeks), was more effective than placebo at reducing pain (RR $>30 \%$ pain, RR 1.38 , 95\% CI 1.22 to 1.56 ), although there was no significant effect at $20-30 \mathrm{mg} /$ day and no difference between doses of 60 and $120 \mathrm{mg} /$ day. NNTB, based on $60 \mathrm{mg} /$ day up to 12 weeks, was $6,95 \%$ CI 3 to 12 . A previous review reported small effects on sleep $(-0.24 ;-0.37$, to -0.12$)$ and disability $(-0.33 ;-0.43$, to -0.24$)$ but no effect on fatigue. ${ }^{30}$ Seven systematic reviews were identified of milnacipran, a recent one of which evaluated five trials. ${ }^{30}$ Patients taking milnacipran were more likely, at the end of treatment, to 
Figure 1 Flow chart identifying eligible reviews.

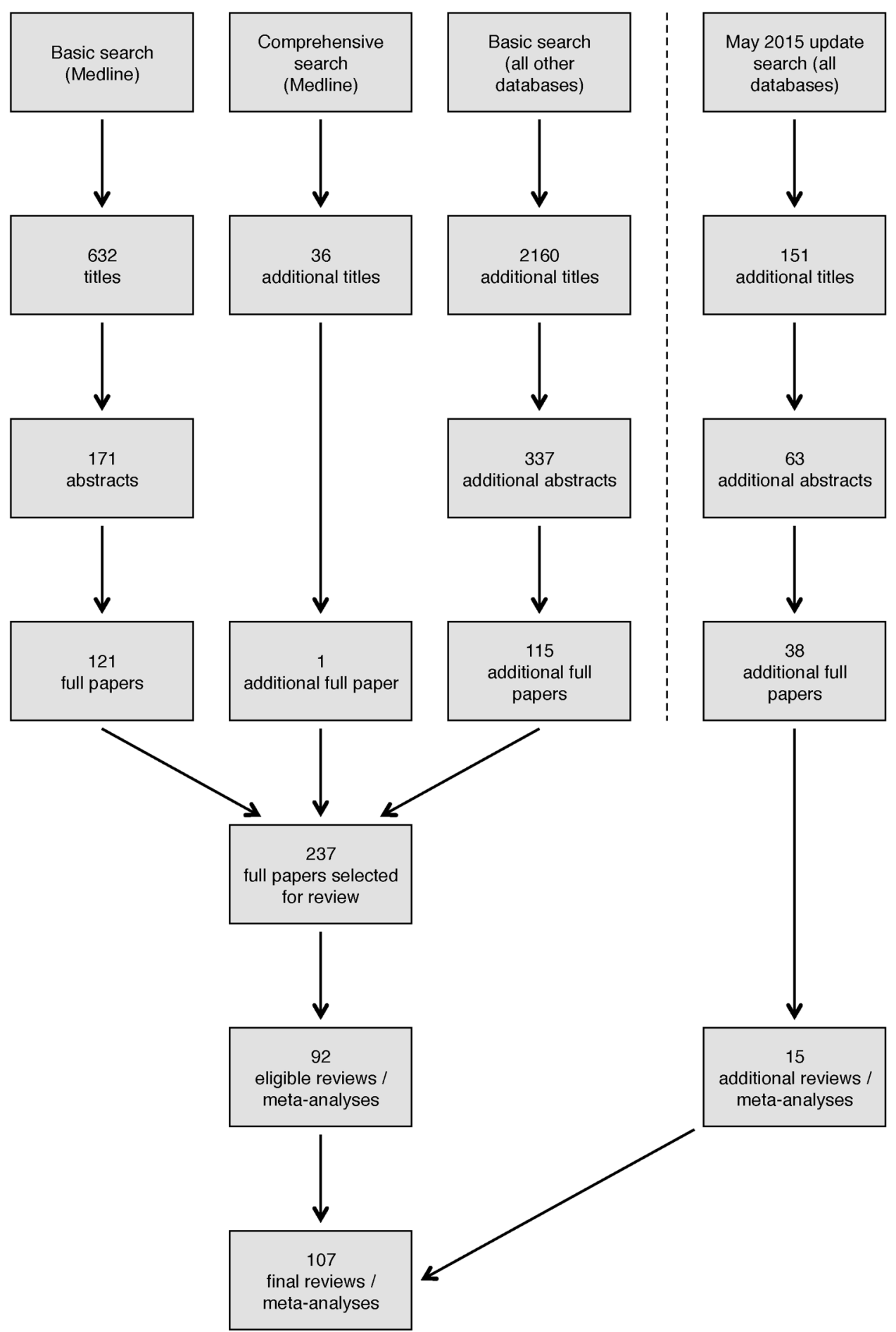

have $30 \%$ pain reduction (RR $1.38,95 \%$ CI 1.25 to 1.51 ) but there was only a small benefit on fatigue $(-0.14 ;-0.19$ to $-0.08)$, disability $(-0.16 ;-0.23$ to -0.10$)$ and no effect on sleep. Duloxetine and milnacipran evaluation: weak for $(100 \%$ agreement).

\section{Selective serotonin reuptake inhibitors}

Seven systematic reviews included up to 11 trials and a maximum of 521 subjects. Given that reviews have not focused on specific drugs or comparisons, drugs within this class were considered together. A recent review of medium quality included seven trials and reported a moderate effect on pain $(-0.40$;
-0.73 , to -0.07$)$, sleep $(-0.31 ;-0.60$ to -0.02$)$ and no effect on fatigue $(-0.17 ;-0.46$ to 0.11$) .{ }^{36}$ Selective serotonin reuptake inhibitor (SSRI) evaluation: weak against (94\% agreement).

\section{Sodium oxybate}

A single systematic review of five studies including 1535 patients reported small effects sizes on pain $(0.44 ; 0.31$ to 0.58$)$, sleep problems $(0.47 ; 0.28$ to 0.66$)$ and fatigue $(0.48 ; 0.35$ to 0.60$)$. The European Medicines Agency and the US Food and Drug Administration refused the approval for FM because of safety concerns. ${ }^{16}$ The drug is only approved for narcolepsy. Sodium oxybate evaluation: strong against (94\% agreement). 
Table 1 Overview of results from selected systematic reviews of placebo-controlled pharmacological trials

\begin{tabular}{|c|c|c|c|c|}
\hline $\begin{array}{l}\text { Treatment } \\
\text { (review reference) }\end{array}$ & $\begin{array}{l}\text { No. of trials } \\
\text { (no. of } \\
\text { participants) } \\
\text { Review quality }\end{array}$ & Dosages; durations of treatment & $\begin{array}{l}\text { Overall trial } \\
\text { quality* }\end{array}$ & Safety and comments \\
\hline Amitriptyline $^{12}$ & $\begin{array}{l}10(767) \\
\text { AMSTAR=6 }\end{array}$ & 10-50 mg/day; 8-24 weeks & Low & $\begin{array}{l}\text { There was no analysis of safety but no difference in } \\
\text { discontinuation rates compared with patients on placebo } \\
\text { was reported. }\end{array}$ \\
\hline $\begin{array}{l}\text { Anticonvulsants- } \\
\text { pregabalin }^{24}\end{array}$ & $\begin{array}{l}5(3256) \\
\text { AMSTAR=10 }\end{array}$ & $\begin{array}{l}\text { Three studies with fixed doses of } 300,450 \text { and } \\
600 \mathrm{mg} / \mathrm{day} \text {; one with fixed doses of } 150,300 \text { or } \\
450 \mathrm{mg} / \mathrm{day} \text {; one flexible dosing study of } 300 \text { or } \\
450 \mathrm{mg} / \mathrm{day} ; 8-14 \text { weeks }\end{array}$ & High & $\begin{array}{l}\text { Increased likelihood of withdrawal due to adverse } \\
\text { events, RR } 1.68,95 \% \mathrm{Cl} 1.36 \text { to } 2.07 ; \mathrm{NNH} 1295 \% \mathrm{Cl} \\
9 \text { to } 17 \text {. No difference in likelihood of serious adverse } \\
\text { events. }\end{array}$ \\
\hline Cyclobenzaprine $^{25}$ & $\begin{array}{l}5 \text { (312) } \\
\text { AMSTAR=7 }\end{array}$ & 10-40 mg; 2-24 weeks & Moderate & $\begin{array}{l}\text { There was no analysis of adverse outcomes in the trials } \\
\text { reviewed although dropout across trials was large } \\
\text { (cyclobenzaprine 29\%, placebo } 43 \% \text { ). Only two studies } \\
\text { conducted ITT. }\end{array}$ \\
\hline Growth hormone ${ }^{16}$ & $\begin{array}{l}2(74) \\
\text { AMSTAR=5 }\end{array}$ & $\begin{array}{l}0.0125 \mathrm{mg} / \mathrm{kg} / \text { day; adjusted to maintain IGF-1 level } \\
\text { of } 250 \mathrm{ng} / \mathrm{mL} \text { after first month, } 0.0125 \mathrm{mg} / \mathrm{kg} / \mathrm{day} \text {; } \\
9 \text { months to } 1 \text { year }\end{array}$ & $\mathrm{NE}$ & $\begin{array}{l}\text { Safety concerns include sleep apnoea and carpal tunnel } \\
\text { syndrome. }\end{array}$ \\
\hline $\mathrm{MAOIs}^{26}$ & $\begin{array}{l}3(241) \\
\text { AMSTAR=9 }\end{array}$ & $\begin{array}{l}\text { Pirlindole } 150 \mathrm{mg} / \mathrm{day} \text {, moclobemide } 150-300 \mathrm{mg} / \\
\text { day; } 4-12 \text { weeks }\end{array}$ & Low & $\begin{array}{l}\text { MAOIs are known to cause potentially fatal hypertensive } \\
\text { crises, serotonin syndrome and psychosis when they } \\
\text { interact with foods containing tyramine and medications } \\
\text { (many of which are commonly used in the treatment of } \\
\text { FM), including SSRIs, tricyclic antidepressants and } \\
\text { tramadol. The clinical trials had restrictions on } \\
\text { concomitant medications. }\end{array}$ \\
\hline NSAIDs $^{21}$ & $\begin{array}{l}2(242) \\
\text { AMSTAR=7 }\end{array}$ & $\begin{array}{l}\text { Ibuprofen } 600 \mathrm{mg} \text { four times a day, tenoxicam } \\
20 \mathrm{mg} / \text { day; } 6-8 \text { weeks }\end{array}$ & Low & $\begin{array}{l}\text { The adverse event profile, although not considered in } \\
\text { this review, is well established for this class of drugs. }\end{array}$ \\
\hline SNRIs—duloxetine ${ }^{31}$ & $\begin{array}{l}6(2249) \\
\text { AMSTAR=10 }\end{array}$ & 20-120 mg/day; 12-28 weeks & Moderate & $\begin{array}{l}\text { Dropout rates due to side effects across studies higher } \\
\text { than with placebo. No difference in serious adverse } \\
\text { events. }\end{array}$ \\
\hline $\begin{array}{l}\text { SNRIs- } \\
\text { milnacipran }^{30}\end{array}$ & $\begin{array}{l}5(4118) \\
\text { AMSTAR=10 }\end{array}$ & 100 or $200 \mathrm{mg} / \mathrm{day} ; 12-27$ weeks & High & $\begin{array}{l}\text { Dropout rates due to side effects across studies were } \\
\text { double compared with placebo, but there was no } \\
\text { difference in serious adverse events. }\end{array}$ \\
\hline SSRIs ${ }^{36}$ & $\begin{array}{l}7(322) \\
\text { AMSTAR=8 }\end{array}$ & $\begin{array}{l}20-40 \mathrm{mg} / \text { day citalopram, } 20-80 \mathrm{mg} / \text { day fluoxetine, } \\
20-60 \mathrm{mg} / \text { day paroxetine; } 6-16 \text { weeks }\end{array}$ & $\begin{array}{l}\text { Moderate to } \\
\text { high }\end{array}$ & $\begin{array}{l}\text { Acceptability and tolerability were similar to placebo } \\
\text { NNH } 40,95 \% \mathrm{Cl} 19 \text { to } 66 \text {. Although several studies } \\
\text { excluded patients with depression/anxiety, Häuser et al }{ }^{26} \\
\text { showed a small effect of SSRIs in improving depressed } \\
\text { mood (SMD }-0.37,95 \% \mathrm{Cl}-0.66 \text { to }-0.07 \text { ). }\end{array}$ \\
\hline Sodium oxybate ${ }^{16}$ & $\begin{array}{l}5(1535) \\
\text { AMSTAR=5 }\end{array}$ & 4.5-6 g/day; 8-14 weeks & $\mathrm{NE}$ & $\begin{array}{l}\text { There is the potential for abuse and central nervous } \\
\text { system effects associated with abuse such as seizure, } \\
\text { respiratory depression and decreased levels of } \\
\text { consciousness. }\end{array}$ \\
\hline Tramadol $^{22}$ & $\begin{array}{l}1(313) \\
\text { AMSTAR=3 }\end{array}$ & $\begin{array}{l}37.5 \mathrm{mg} \text { tramadol } / 325 \mathrm{mg} \text { paracetamol } 4 \times / \text { day; } \\
3 \text { months }\end{array}$ & High & $\begin{array}{l}\text { No significant difference in discontinuation due to } \\
\text { adverse events (RR } 1.62,95 \% \mathrm{Cl} 0.94 \text { to } 2.80 \text { ). A } \\
\text { high-quality review (AMSTAR score } 7 \text { ) identified a single } \\
\text { study, which, among persons who tolerated and } \\
\text { benefitted from tramadol, demonstrated a lower } \\
\text { discontinuation rate in a double-blind phase compared } \\
\text { with placebo. }{ }^{21}\end{array}$ \\
\hline
\end{tabular}

\footnotetext{
${ }^{*}$ According to the method of quality evaluation used in the review.
}

AMSTAR, Assessing the Methodological Quality of Systematic Reviews; FM, fibromyalgia; IGF, insulin growth factor; ITT, intention-to-treat; MAOIs, monoamine oxidase inhibitors; NE, not evaluated; NNH, number needed to harm; NSAIDs, non-steroidal anti-inflammatory drugs; RR, risk ratio; SMD, standardised mean difference; SNRI, serotonin-noradrenalin reuptake inhibitor; SSRI, selective serotonin reuptake inhibitor.

Tramadol, a weak opioid with mild serotonin-noradrenalin reuptake inhibitor (SNRI) activity was considered by two reviews. Roskell et $a l^{22}$ identified a single study of tramadol with paracetamol. Those in the active arm were more likely to have $30 \%$ improvement in pain (RR $1.77,95 \% \mathrm{CI}$ 1.26 to 2.48). Tramadol evaluation: weak for (100\% agreement).

The literature search did not identify any reviews on corticosteroids, strong opioids, cannabinoids and antipsychotics. The committee made a 'strong against' evaluation (100\% agreement) regarding the use of strong opioids and corticosteroids in patients with fibromyalgia on the basis of lack of evidence of efficacy and high risk of side effects/addiction reported in individual trials.

\section{Evaluation of non-pharmacological therapies; complementary and alternative medicines and therapies Acupuncture}

Eight reviews included up to 16 trials and 1081 participants. One high-quality review included nine trials, with 395 patients, and demonstrated that acupuncture, added to standard therapy, resulted in a $30 \%(21 \%, 39 \%)$ improvement in pain. ${ }^{70}$ Electric acupuncture was also associated with improvements in pain $(22 \% ; 4 \%$ to $41 \%)$ and fatigue $(11 \% ; 2 \%$ to $20 \%)$. Some adverse events were reported, but these were commonly mild and transient. There is little understanding of the active component of acupuncture, and the evidence supporting the use of real versus sham acupuncture was less consistent. Acupuncture evaluation: weak for (93\% agreement). 
Table 2 Overview of results from selected systematic reviews of non-pharmacological; complementary and alternative medicine and therapy trials

\begin{tabular}{|c|c|c|c|c|}
\hline $\begin{array}{l}\text { Treatment } \\
\text { (review reference) }\end{array}$ & $\begin{array}{l}\text { No. of trials } \\
\text { (no. of participants*) } \\
\text { Review quality }\end{array}$ & Dosages; durations of treatment & $\begin{array}{l}\text { Overall trial } \\
\text { qualityt }\end{array}$ & Safety and comments \\
\hline Acupuncture $^{70}$ & $\begin{array}{l}9(395) \\
\text { AMSTAR=11 }\end{array}$ & $\begin{array}{l}\text { Treatment sessions ranged from } 3 \text { to } 13 \text { weeks (median=4), with needle retention } \\
\text { ranging from } 20 \text { to } 30 \text { min. Only one study provided journal references for the } \\
\text { acupuncture point selection, and the description of the type of needle stimulation/ } \\
\text { manipulation was clear in only three studies. }\end{array}$ & Moderate & $\begin{array}{l}\text { One in six people who had acupuncture, and one in three controls, reported adverse } \\
\text { events. Such events were minor and lasted less than one day. No serious adverse events } \\
\text { were reported in any trials. }\end{array}$ \\
\hline Biofeedback $^{92}$ & $\begin{array}{l}7(321) \\
\text { AMSTAR=8 }\end{array}$ & $\begin{array}{l}\text { EMG biofeedback. } \\
\text { Individual sessions varied between } 45 \text { and } 180 \mathrm{~min} \text {, and the number of sessions varied } \\
\text { between } 6 \text { and } 16 . \\
\text { EEG biofeedback. } \\
20-22 \text { sessions of (where reported) } 30 \text { min duration. }\end{array}$ & Poor & $\begin{array}{l}\text { Only two } \text { trials reported adverse event data. } 4 \% \text { of patients in one trial receiving EMG } \\
\text { biofeedback reported stress. And } 74 \% \text { of patients in another, receiving EEG biofeedback } \\
\text { reported a variety of side effects, including: headache, fatigue and sleep problems. }\end{array}$ \\
\hline Capsaicin $^{94}$ & $\begin{array}{l}2(153) \\
\text { AMSTAR=5 }\end{array}$ & $\begin{array}{l}\text { Topical application of Capsicum annuum L. cream, either } \\
0.025 \% \text { capsaicin for } 4 \text { weeks or } 0.075 \% \text { for } 12 \text { weeks. }\end{array}$ & Not reported & Patients reported moderate, transient, burning or stinging. \\
\hline Chiropractic $^{89}$ & $\begin{array}{l}3(102) \\
\text { AMSTAR=4 }\end{array}$ & $\begin{array}{l}\text { Little detail is given for any trials, but treatment elements included massage, stretching, } \\
\text { spinal manipulation, education and resistance training. }\end{array}$ & Low & $\begin{array}{l}\text { Around } 50 \% \text { of patients experience mild-to-moderate transient adverse effects after } \\
\text { spinal manipulation.§ }\end{array}$ \\
\hline $\mathrm{CBT}^{57}$ & $\begin{array}{l}23(2031) \\
\text { AMSTAR }=11\end{array}$ & $\begin{array}{l}\text { Median duration of therapy }=10 \text { weeks, with a median number of } 10 \text { sessions, and } \\
\text { median total hours }=18 \text { hours. All but two studies delivered therapy face to face. Median } \\
\text { follow-up (where this was performed } 17 / 23 \text { studies) }=6 \text { months. }\end{array}$ & Low & $\begin{array}{l}\text { The assessment of safety in most studies was insufficient. } \\
\text { Two studies reported dropout due to worsening of comorbid mental disorders. However, } \\
\text { CBT is generally considered safe. }\end{array}$ \\
\hline Exercise $^{41}$ & $\begin{array}{l}34(2276) \\
\text { AMSTAR=9 }\end{array}$ & $\begin{array}{l}\text { Exercise programmes lasting } 2.5-24 \text { weeks. Aerobic exercise for } \geq 20 \mathrm{~min} \text {, once a day (or } \\
\text { twice for } \geq 10 \mathrm{~min}), 2-3 \text { days a week. Strength training with } \geq 8 \text { repetitions per exercise, } \\
2-3 \text { times a week. }\end{array}$ & Moderate & $\begin{array}{l}\text { Although patients may initially notice a deterioration in symptoms, exercise is generally } \\
\text { considered safe, especially when practised under supervision. }\end{array}$ \\
\hline $\begin{array}{l}\text { Hydrotherapy/spa } \\
\text { therapy }^{76}\end{array}$ & $\begin{array}{l}10(446) \\
\text { AMSTAR=9 }\end{array}$ & $\begin{array}{l}\text { Wide variation in precise treatment strategy between trials. Most consisted of water or } \\
\text { mud baths at body temperature } 36-37^{\circ} \mathrm{C} \text {, or slightly above }\left(40-45^{\circ} \mathrm{C}\right) \text {, with a median } \\
\text { treatment time of } 240 \text { min (range } 200-300 \text { ), over several weeks. }\end{array}$ & Low & $\begin{array}{l}\text { Three studies reported no side effects of treatment; one reported slight flashes in } 10 \% \text { of } \\
\text { the patients. The remaining trials did not explicitly mention safety. }\end{array}$ \\
\hline Hypnotherapy ${ }^{91}$ & $\begin{array}{l}4(152) \\
\text { AMSTAR=11 }\end{array}$ & $\begin{array}{l}\text { Some variation between trials ranging (where reported) from } 300 \text { to } 420 \mathrm{~min} \text {, delivered } \\
\text { over } 10-26 \text { weeks. }\end{array}$ & Good & Adverse events were not reported in any of the trials. \\
\hline Massage $^{63}$ & $\begin{array}{l}9(404) \\
\text { AMSTAR }=7\end{array}$ & $\begin{array}{l}\text { Massage therapy time lasted } 25-90 \mathrm{~min} \text {, with between } 1 \text { and } 20 \text { massage sessions in } \\
\text { total. }\end{array}$ & Low to moderate & No adverse events were reported in any of the trials. \\
\hline Meditative movement ${ }^{80}$ & $\begin{array}{l}7(362) \\
\text { AMSTAR=9 }\end{array}$ & $\begin{array}{l}\text { Wide variation in treatments between trials, and included yoga, tai chi, qigong or body } \\
\text { awareness therapy. Median (range) duration of treatment }=16(6-24) \text { hours, over } \\
4-12 \text { weeks. }\end{array}$ & Moderate & $\begin{array}{l}\text { Although no serious adverse events were reported, six participants ( } 3.1 \%) \text { withdrew from } \\
\text { the trials because of adverse events (increase of pain; muscle inflammation; chlorine } \\
\text { hypersensitivity). The review authors concluded that the acceptance and safety of all } \\
\text { types of meditative movement therapies were high. }\end{array}$ \\
\hline $\begin{array}{l}\text { Mindfulness/mind-body } \\
\text { therapy }^{84}\end{array}$ & $\begin{array}{l}6(674) \\
\text { AMSTAR }=9\end{array}$ & $\begin{array}{l}\text { Some variation between trials. Single } 2-3.5 \text { hours session per week, for } 8-10 \text { weeks. } \\
\text { Four out of six programmes also included daily home practice }(30-45 \mathrm{~min}) \text { plus a single } \\
\text { all-day retreat. }\end{array}$ & Low & Safety was assessed and reported in none of the trials. \\
\hline $\begin{array}{l}\text { Multicomponent } \\
\text { therapy }\end{array}$ & $\begin{array}{l}9(1119) \\
\text { AMSTAR=9 }\end{array}$ & $\begin{array}{l}\text { Enormous variation in treatment strategies between trials. Most included different } \\
\text { combinations of exercise (land and/or water based); education; relaxation; and/or some } \\
\text { other specific therapeutic component (eg, Tai Chi; or massage). }\end{array}$ & Moderate & No adverse events were reported in any of the trials. \\
\hline $\mathrm{SAMe}^{93}$ & $\begin{array}{l}1(44) \\
\text { AMSTAR }=6\end{array}$ & $400 \mathrm{mg}$ tablet, twice a day, for 6 weeks. & Moderate & Mild adverse effects such as stomach upset and dizziness were reported. \\
\hline $\begin{array}{l}\text { Other: guided } \\
\text { imagery }\end{array}$ & $\begin{array}{l}1(48) \\
\text { AMSTAR=9 }\end{array}$ & $\begin{array}{l}\text { Audiotape-led, individual, guided imagery: } 30 \text { min daily for } 6 \text { weeks recommended. } \\
\text { Median of } 44 \text { exercises (range 37-136). }\end{array}$ & Good & Adverse events were not reported. \\
\hline Other: homeopathy ${ }^{98}$ & $\begin{array}{l}4(163) \\
\text { AMSTAR }=7\end{array}$ & $\begin{array}{l}\text { Variation between trials. Two studied individualised homeopathic treatment, consisting of } \\
\text { an initial consultation (and treatment), plus follow-up interviews every } 4-8 \text { weeks. Two } \\
\text { studied Arnica montana, Bryonia alba or Rhus toxicodendron (potency } 6 c \text { ) daily for } \\
\text { between } 1 \text { and } 3 \text { months. }\end{array}$ & Low to moderate & No information was provided on safety. \\
\hline
\end{tabular}

${ }^{*}$ Total number of persons randomised.

tAccording to the method of quality evaluation used in the review.

\#Elsewhere in the review, it reports that three studies reported on adverse events. However, in the table where these data are presented, it is only clear for two. However, in a third trial, there were no dropouts due to side effects.

$\S$ These data were not contained in this review. The initial recommendation for chiropractic was weak against. However, after discussion, this was downgraded to strong against due to potential safety concerns.

CBT, cognitive behavioural therapy; EMG, electromyographic; SAMe, S-adenosyl methionine.

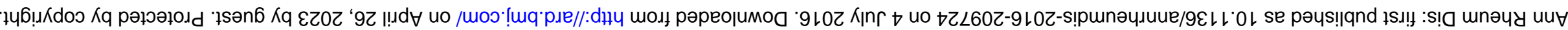




\section{Biofeedback}

Two reviews included up to seven trials and 307 participants. Glombiewski et $a l^{92}$ reviewed seven studies, comprising 321 participants. Treatment sessions varied from 6 to 22; with control therapy comprising sham biofeedback, attention control, medication and treatment as usual. Biofeedback was effective in reducing pain intensity (Hedges' $\mathrm{g}=0.79 ; 0.22$ to 1.36 ), although all trials were poor quality. There was no evidence of effectiveness in terms of fatigue or sleep and subgroup analysis suggested that any effect was limited to electromyographic $(0.86 ; 0.11$ to 1.62$)$ rather than electroencephalographic biofeedback $(0.71 ;-0.37$ to 1.8$)$. Biofeedback evaluation: weak against $(100 \%$ agreement).

\section{Capsaicin}

Two reviews included two trials and 153 participants. The most recent review, a narrative review of two trials, considered data on 153 patients. $^{94}$ Both showed some evidence of positive effect in terms of pain relief, although results were not consistent for other outcomes. Capsaicin gel is generally considered safe, although many users report a mild burning sensation when applied to the skin. However, the number of patients and trials was small and was therefore limited in the extent to which they can provide evidence for toxicity. Capsaicin evaluation: weak against (86\% agreement).

\section{Chiropractic}

Three reviews included up to 13 trials and 102 participants. The most recent review summarised three studies. ${ }^{89}$ One study was an open pilot study, one quasi-randomised and in the third no between-group differences were observed in terms of pain. The studies were poor quality and lacked robust interpretable data. Chiropractic evaluation: strong against (93\% agreement).

\section{Cognitive behavioural therapies}

Five reviews included up to 30 trials and at least 2031 participants. One high-quality review included 23 trials, comprising $>2000$ patients, although the quality of individual trials was reported as generally poor. ${ }^{58}$ Cognitive behavioural therapies (CBTs) were effective in reducing pain $(-0.29 ;-0.49$ to -0.17$)$ and disability $(-0.30 ;-0.51$ to -0.08$)$ at the end of treatment compared with a variety of controls groups, and results were sustained long term. Behavioural therapy evaluation: weak for (100\% agreement).

\section{Exercise}

Twenty reviews included up to 34 trials and at least 2494 participants. ${ }^{\text {ii }}$ The largest, a Cochrane review, considered 47 different exercise interventions. ${ }^{41}$ Aerobic exercise was associated with improvements in pain $(0.65 ;-0.09$ to 1.39$)$ and physical function $(0.66 ; 0.41$ to 0.92$)$. Busch et $a l^{42}$ reviewed five trials with 219 participants and concluded that resistance training resulted in a significant improvement in pain $(-3.3 \mathrm{~cm}$ on a $10 \mathrm{~cm}$ scale; -6.35 to -0.26$)$ as well as function compared with control. There is some consistency with regard to aerobic and strengthening exercises, although insufficient evidence to suggest superiority of one over the other; land and aquatic exercise appear equally effective. ${ }^{56}$ Exercise therapy evaluation: strong for (100\% agreement).

\footnotetext{
ii It is unclear from some of the reviews how many participants were included. The number of participants represents the minimum about
} which we can be confident.

\section{Hydrotherapy/spa therapy}

Four reviews included up to 21 trials and 1306 participants. One high-quality review included 10 trials, 446 participants and compared a median of 4-hour hydrotherapy (range 200$300 \mathrm{~min}$ ) against various comparators. ${ }^{76}$ There was a significant improvement in pain $(-0.78 ;-1.42$ to -0.13$)$ at the end of therapy, maintained in the longer term (median 14 weeks), although the review authors noted that no trials conducted an ITT analysis. There was consistency with regard to the evidence for hydrotherapy and balneotherapy, although little evidence to suggest superiority of one over the other. ${ }^{77}$ Hydrotherapy evaluation: weak for (93\% agreement).

\section{Hypnotherapy}

One review included four trials, although the number of participants is unclear. ${ }^{91}$ Although six trials of hypnotherapy and/or guided imagery were reviewed, only four examined hypnotherapy in isolation. Median treatment duration (where reported) was $360 \mathrm{~min}$ and hypnotherapy was compared with a variety of control therapies: cognitive intervention, active control (physical therapy/massage/relaxation/autogenic training) and treatment as usual. A meta-analysis is presented on all six trials, and isolated data for hypnotherapy are not presented. Two of the four hypnotherapy trials report some significant benefit in terms of pain, the other two demonstrate null, non-significant results. Hypnotherapy evaluation: weak against (86\% agreement).

\section{Massage}

Six reviews have been reported and one meta-analysis with nine trials and 404 patients ${ }^{63}$ with sessions lasting $25-90 \mathrm{~min}$, and treatment duration ranging from 1 to 24 weeks (median 5 weeks). Comparator treatments included transcutaneous electrical nerve stimulation (TENS), standard care, guided relaxation and acupuncture. Methodological problems were noted with all of the studies, only four were at low risk of bias in terms of random allocation and only two were analysed as ITT. Overall, massage was not associated with a significant improvement in pain $(0.37 ;-0.19$ to 0.93$)$, and of the two ITT analyses, one favoured massage and one favoured control (both significant). A subgroup analysis revealed some evidence of a positive effect with massage of $\geq 5$ weeks duration, although this was based solely on lower-quality trials. Massage evaluation: weak against (86\% agreement).

\section{Meditative movement}

Six reviews, including up to eight trials and 559 participants, focused on qigong, yoga, tai chi or a combination of these therapies. However, there was insufficient evidence to make individual recommendations. One review included seven trials, with 362 participants randomised to tai chi, yoga, qigong or body awareness therapy. ${ }^{80}$ Total treatment time ranged from 12 to 24 hours and was compared with a variety of controls, including treatment as usual and active control groups (aerobics, wellness education and stretching). At the end of therapy, improvements were seen in sleep $(-0.61 ;-0.95$ to -0.27$)$ and fatigue $(-0.66 ;-0.99$ to -0.34$)$ some of which were maintained in the longer term. Meditative movement evaluation: weak for (71\% agreement).

\section{Mindfulness/mind-body therapy}

Six reviews included up to 13 trials and 1209 participants. One recent review, a meta-analysis of six trials, with 674 patients ${ }^{84}$ provided evidence that mindfulness-based stress reduction 
resulted in improvements in pain $(-0.23 ;-0.46$ to -0.01$)$ immediately post treatment compared with usual care and compared with active control interventions $(-0.44 ;-0.73$ to -0.16). However, these effects were not robust against bias. Mindfulness/mind-body therapy evaluation: weak for $(73 \%$ agreement).

\section{Multicomponent therapy}

Two reviews including up to 27 trials and 2407 participants examined the additional benefit of combining therapies compared with individual therapy. Häuser et $a l^{60}$ conducted a review of management involving both educational or psychological therapies and exercise. In a meta-analysis of nine trials and 1119 patients, multicomponent therapy was effective in reducing pain $(-0.37 ;-0.62$ to -0.13 ), and fatigue, immediately post treatment, compared with waiting list, relaxation, treatment as usual and education. However, effects were short-lived. Multicomponent therapy evaluation: weak for (93\% agreement).

\section{S-Adenosyl methionine}

Two reviews each included one trial with, in combination, 74 participants. De Silva et $a l^{93}$ reported that, after the end of treatment, significant improvements were observed in pain and fatigue compared with placebo. Sim and Adams ${ }^{52}$ reviewed a trial comparing $S$-adenosyl methionine (SAMe) with TENS but data on the main trial comparison are omitted. Side effects are usually mild and infrequent. However, the number of patients and trials was small and therefore cannot provide a robust assessment of toxicity and safety. SAMe evaluation: weak against (93\% agreement).

\section{Other complementary and alternative therapies}

Three reviews of guided imagery included up to six trials and 357 participants. The highest quality, including only one trial, provided some evidence that guided imagery may be effective in reducing pain $(-1.52 ;-2.17$ to -0.87$) .{ }^{90}$ Two reviews of homeopathy included four trials and 163 participants. ${ }^{97} 98$ Both contained a review including only four randomised trials, each of which showed some benefit of homeopathy, on some outcomes. However, none of the individual trials were without serious flaws. Other complementary and alternative therapies (guided imagery, homeopathy): strong against (93\% agreement).

Reviews were identified that examined electrothermal and phototherapeutic therapy; ${ }^{99}$ phytothermotherapy; ${ }^{100}$ music therapy, journaling/storytelling ${ }^{103}$ and static magnet therapy, ${ }^{101}$ although each was insufficient to allow a recommendation. Marlow et al ${ }^{102}$ examined the effectiveness of transcranial magnetic and/or direct current stimulation. Eight trials included 244 participants, although not all were analysed by ITT, and appropriate group comparisons were not presented for all studies. Overall, there was little evidence to support either therapy, and several studies reported an unacceptably high rate of adverse events and/or discontinuation due to headache.

\section{EULAR revised recommendations}

In terms of overall principles, we recommend, based on unanimous expert opinion, that optimal management requires prompt diagnosis and providing the patient with information (including written material) about the condition. There should be a comprehensive assessment of pain, function and the psychosocial context. Management should take the form of a graduated approach with the aim of improving health-related quality of life. It should focus first on non-pharmacological modalities. This is based on availability, cost, safety issues and patient preference.
We have used the evaluation of individual therapies (above) to make 10 specific recommendations, all based on evidence from systematic reviews and all but one from meta-analysis. The recommendations are given in table 3 , and a flow chart of how these therapies may be used in management is shown in figure 2 .

We were unanimous in providing a 'strong for' recommendation for the use of exercise, particularly given its effect on pain, physical function and well-being, availability, relatively low cost and lack of safety concerns. The available evidence did not allow us to distinguish between the benefits of aerobic or strengthening. We gave 'weak for' recommendations in relation to meditative movement therapies (which improved sleep, fatigue and quality of life) or mindfulness-based stress reduction (which improved pain and quality of life); the physical therapies acupuncture or hydrotherapy for which there was evidence that they improved pain/fatigue and pain/quality of life, respectively. The effects seen in pragmatic trials of such therapies will include specific and non-specific effects, and it is not possible to disentangle these. There were some non-pharmacological therapies we did not recommend because of lack of effectiveness and/or low study quality: biofeedback, capsaicin, hypnotherapy, massage, SAMe and other complementary and alternative therapies. We provided a 'strong against' evaluation for chiropractic based on safety concerns.

In case of lack of effect of the above therapeutic approaches, we recommend individualised treatment according to patient need. Psychological therapies ('weak for') should be considered for those with mood disorder or unhelpful coping strategies: CBT was effective at producing modest, long-term reductions in pain, disability and improving mood. Pharmacological therapies (all 'weak for') should be considered for those with severe pain (duloxetine, pregabalin, tramadol) or sleep disturbance (amitriptyline, cyclobenzaprine, pregabalin). Multimodal rehabilitation ('weak for') programmes should be considered for those with severe disability - in comparison to individual therapies, those that were multimodal improved a range of short-term outcomes. We did not recommend several pharmacological therapies including NSAIDs, MAOIs and SSRIs because of lack of efficacy and specifically gave a 'strong against' evaluation to growth hormone, sodium oxybate, strong opioids and corticosteroids based on lack of efficacy and high risk of side effects.

\section{DISCUSSION}

The previous EULAR recommendations provided an important milestone in the management of fibromyalgia. There were nine recommendations, but only three were supported by strong evidence from the scientific literature; most were based on expert opinion. Since that time, there have been a considerable number of trials published addressing issues in the management of fibromyalgia. The availability of systematic reviews and meta-analysis of randomised controlled trials (RCTs) for all the most common approaches to management allowed us to concentrate on these.

\section{Comparison with 2007 EULAR recommendations}

Despite the very large increase in the amount of trial data and summarised in meta-analyses, there are no major changes to the approach of managing patients with fibromyalgia, although we provide new evidence in support for some additional nonpharmacological therapies. In addition, all the recommendations are now firmly evidence based. We now recommend that nonpharmacological therapy should be first-line therapy and then if there is a lack of effect that there should be individualised 
Table 3 Recommendations

\begin{tabular}{|c|c|c|c|c|}
\hline Recommendation & $\begin{array}{l}\text { Level of } \\
\text { evidence }\end{array}$ & Grade & $\begin{array}{l}\text { Strength of } \\
\text { recommendation }\end{array}$ & $\begin{array}{l}\text { Agreement } \\
(\%)^{*}\end{array}$ \\
\hline \multicolumn{5}{|l|}{ Overarching principles } \\
\hline $\begin{array}{l}\text { Optimal management requires prompt diagnosis. Full understanding of fibromyalgia requires comprehensive } \\
\text { assessment of pain, function and psychosocial context. It should be recognised as a complex and heterogeneous } \\
\text { condition where there is abnormal pain processing and other secondary features. In general, the management of } \\
\text { FM should take the form of a graduated approach. }\end{array}$ & IV & D & & 100 \\
\hline $\begin{array}{l}\text { Management of fibromyalgia should aim at improving health-related quality of life balancing benefit and risk of } \\
\text { treatment that often requires a multidisciplinary approach with a combination of non-pharmacological and } \\
\text { pharmacological treatment modalities tailored according to pain intensity, function, associated features (such as } \\
\text { depression), fatigue, sleep disturbance and patient preferences and comorbidities; by shared decision-making with } \\
\text { the patient. Initial management should focus on non-pharmacological therapies. }\end{array}$ & IV & D & & 100 \\
\hline \multicolumn{5}{|l|}{ Specific recommendations } \\
\hline \multicolumn{5}{|l|}{ Non-pharmacological management } \\
\hline Aerobic and strengthening exercise & la & A & Strong for & 100 \\
\hline Cognitive behavioural therapies & la & A & Weak for & 100 \\
\hline Multicomponent therapies & la & A & Weak for & 93 \\
\hline Defined physical therapies: acupuncture or hydrotherapy & la & A & Weak for & 93 \\
\hline Meditative movement therapies (qigong, yoga, tai chi) and mindfulness-based stress reduction & la & A & Weak for & $71-73$ \\
\hline \multicolumn{5}{|l|}{ Pharmacological management } \\
\hline Amitriptyline (at low dose) & la & A & Weak for & 100 \\
\hline Duloxetine or milnacipran & la & A & Weak for & 100 \\
\hline Tramadol & $\mathrm{lb}$ & A & Weak for & 100 \\
\hline Pregabalin & la & A & Weak for & 94 \\
\hline Cyclobenzaprine & la & $A$ & Weak for & 75 \\
\hline
\end{tabular}

*Percentage of working group scoring at least 7 on $0-10$ numerical rating scale assessing agreement.

therapy according to patient need, which may include pharmacological therapy.

\section{Comparison with other recommendation}

There are three recent guidelines on the management of FM from Canada, Israel and Germany that have been compared with respect to their recommendations. ${ }^{105}$ These guidelines and our EULAR recommendations are in agreement on the principles of approach to management, the need for tailored therapy to the individual and the first-line role of nonpharmacological therapies. There are differences between our guidelines and previous guidelines, which can partly be explained by us using more recently available evidence. There are differences in the strength of recommendations relating to pharmacological therapies: anticonvulsants and SNRIs were strongly recommended by the Canadian and Israeli guidelines while the German and these EULAR guidelines provide a weak recommendation. There are also differences in relation to individual non-pharmacological therapies across guidelines in terms of whether they were assessed. For example, meditative movement is strongly recommended by the German guidelines, but recommended only for a minority of patients in Israel, while these EULAR guidelines provide a 'weak for' recommendation.

The committee recommended that an update is conducted after 5 years in order to determine whether for those therapies with relatively little current evidence further trials have been conducted and, second, whether any new therapies have emerged for the management of fibromyalgia.

\section{Research priorities}

In the course of discussion, we identified important questions in terms of guiding management where there was either insufficient (or often no) evidence base to guide decisions, that is, 'research gaps'. We discussed their relatively priority taking into account their potential to guide management, the likelihood that such studies could be conducted and were likely to be funded. We identified five such priority questions:

- Which type of exercise is most effective: strength and/or aerobic training?

- Are combined pharmacological and non-pharmacological approaches to management more effective than singlemodality management?

- Are there characteristics of patients with fibromyalgia that predict response to specific therapies?

- How should fibromyalgia be managed when it occurs as a comorbidity to inflammatory arthritis?

- What aspects of a healthcare system optimise outcome for patients (who is best for the management of FM patients)?

Some of these questions are best answered by RCTs. Given, however, the expense of such studies and that they can take almost 10 years from identifying the questions to be answered to results being obtained, alternatives including registers and observational studies should be considered. These can be complemented by qualitative studies to determine the needs of patients.

\section{Dissemination}

These recommendations will be disseminated by the international working group through national rheumatology societies. This will include scientific meetings, newsletters and continuing education programmes. We will produce a summary of the recommendations suitable for dissemination through EULAR-affiliated patient groups and through national patient societies. We will investigate assessing agreement with the recommendations in the target population. 


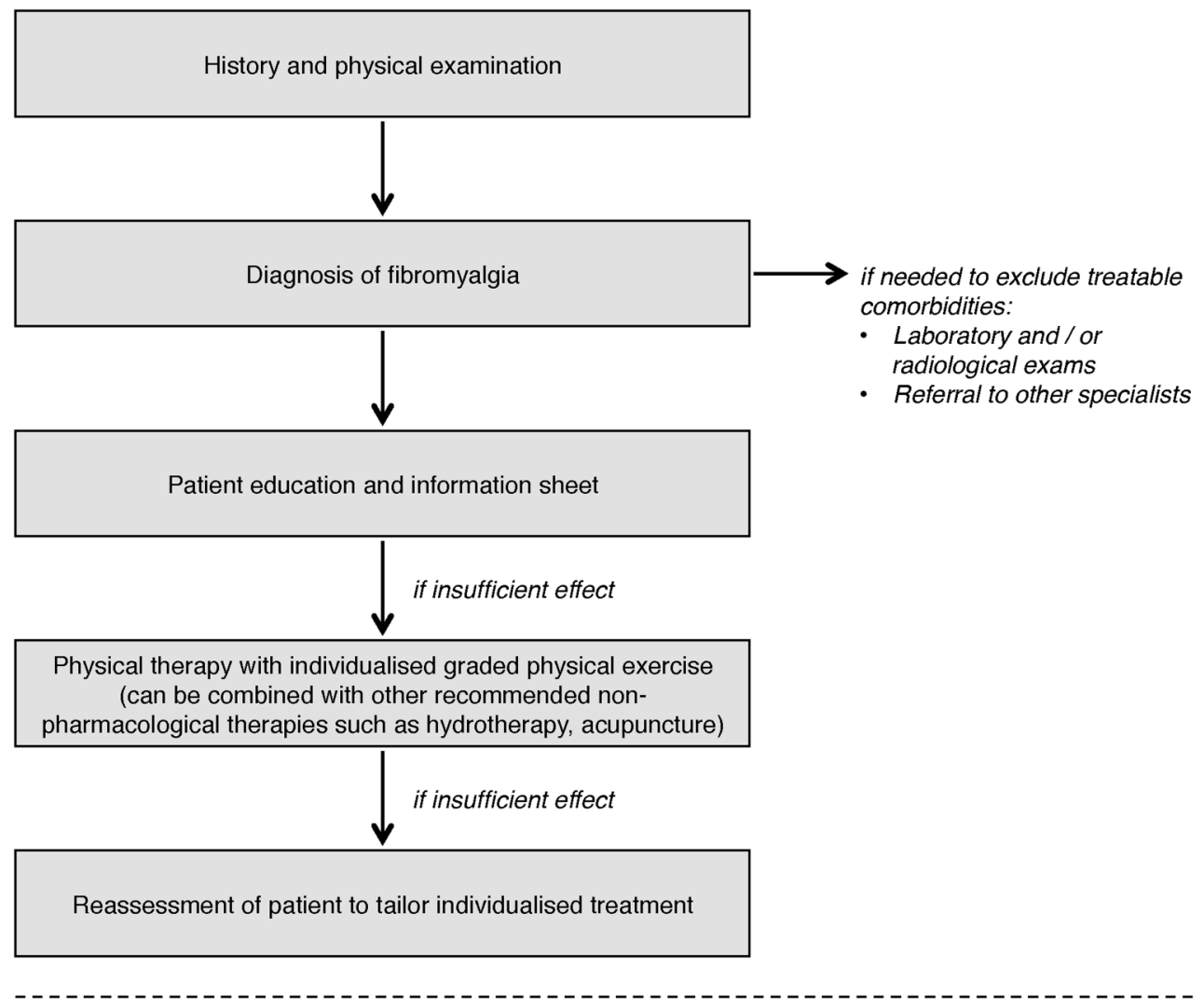

Additional individualised treatment
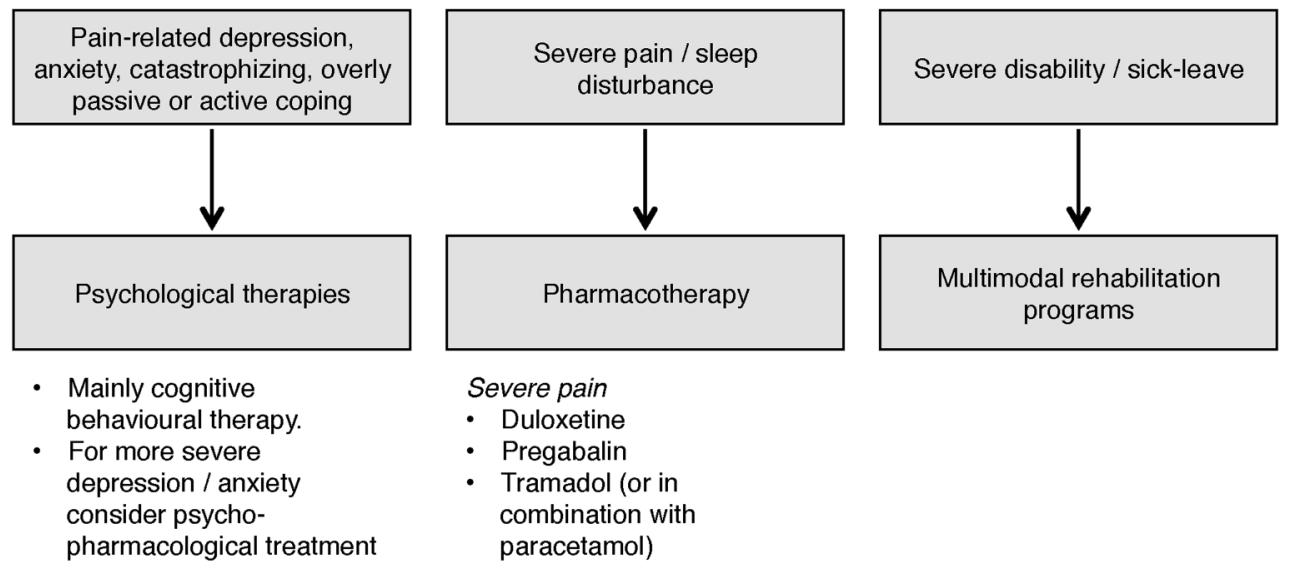
Severe pain
- Duloxetine
- Pregabalin
- Tramadol (or in combination with paracetamol)
Severe sleep problems
- Low dose amitriptyline
- Cyclobenzaprine or
- Pregabalin at night

Figure 2 Management recommendations as flow chart.

\section{SUMMARY}

In summary, these revised EULAR recommendations newly incorporate a decade of evidence in relation to the pharmacological and non-pharmacological management of fibromyalgia. They allow EULAR to move from recommendations that are predominantly based on expert opinion to ones that are firmly based on scientific evidence from high-quality reviews and meta-analyses. Despite this evidence, however, the size of effect for many treatments is relatively modest. We propose focusing on the research priorities we outline to address issues clarifying to whom certain interventions may best be delivered, their effect in combination, matching patients to therapies and the organisation of healthcare systems to optimise outcome.

\section{Author affiliations}

${ }^{1}$ Epidemiology Group, School of Medicine, Medical Sciences and Nutrition, University of Aberdeen, Aberdeen, UK

${ }^{2}$ Department of Rheumatology, Cantonal Hospital, Fribourg, Switzerland

${ }^{3}$ ICRCCS Galeazzi Orthopaedic Institute, Milan, Italy 
${ }^{4}$ Department of Internal Medicine I, Klinikum Saarbrücken, Saarbrücken, Germany ${ }^{5}$ Department of Psychosomatic Medicine, Technische Universität München, München, Germany

${ }^{6}$ Section of Rheumatology, Institute of Infection and Immunity, Cardiff University School of Medicine, Cardiff, UK

${ }^{7}$ Department of Clinical Neuroscience, Karolinska Institutet and Stockholm Spine Centre, Stockholm, Sweden

${ }^{8}$ Department of Rheumatology, Bispebjerg and Frederiksberg, The Parker Institute, Copenhagen University Hospital, Copenhagen, Denmark

${ }^{9}$ Rheumatology Department, CEDOC-NOVA Medical School, UNL, CHLO, Hospital Egas Moniz, Lisbon, Portugal

${ }^{10}$ Hacettepe University Division of Internal Medicine, Department of Physical and Rehabilitation Medicine, Ankara, Turkey

${ }^{11}$ Finnish Institute of Occupational Health, Helsinki, Finland

${ }^{12}$ Patient Representative, Bristol, UK

${ }^{13}$ Mater Misericordiae University Hospital, Dublin, Ireland

${ }^{14}$ Patient Representative, Limassol, Cyprus

${ }^{15}$ Centre de la Douleur, Hôpital Cochin-Hôtel Dieu, Université Paris Descartes, Paris, France

${ }^{16}$ Rheumatology Unit, L. Sacco University Hospital, Milan, Italy

${ }^{17}$ Institute of Infection and Immunity, Cardiff University School of Medicine, Cardiff, UK

Twitter Follow Gary Macfarlane at @UAberdeenEpi

Contributors GJM, FA, PS-P, EC and GTJ were applicants on the grant. EF and LED undertook the literature search and together with FA identified eligible reviews. EF, LED, FA and CK evaluated the quality of each of the eligible reviews. GTJ led the evaluation of non-pharmacological therapies and FA and CK led the evaluation of pharmacological therapies. GJM drafted the manuscript with input from GTJ, WH, EC, CK and EK. All authors (with the exception of FA and EF) participated in a 2-day project meeting, and all authors made important intellectual contributions to the manuscript.

Funding The project was funded by EULAR.

Competing interests CK undertook work in this project supported by a fellowship from the Swiss Society for Rheumatology. SP has received personal fees from Pierre Fabre, Pfizer, Eli Lilly and Jazz pharmaceutical (advisory boards and research activities). EC has received personal fees from Pfizer, Eli Lilly and Tonix (advisory boards and speaker fees). WH has received personal fees from MSD and Grünenthal (speaker fees), was head of the steering committee of the German quidelines on fibromyalgia and is a member of the medical board of the German Fibromyalgia Association. GJM has received personal fees from Pfizer (research activities). EK reports personal fees from Lundbeck, Orion and research funding from Eli Lilly. GMM reports personal fees from Pfizer, A Menarini, Hospiri and BMS, and has received research funding from AbbVie and Pfizer. PS-P reports personal fees from Abbott, Roche, Pfizer, UCB, MSD and has received research funding from Pfizer, UCB, Roche.

Provenance and peer review Not commissioned; externally peer reviewed.

\section{REFERENCES}

1 Queiroz LP. Worldwide epidemiology of fibromyalgia. Curr Pain Headache Rep 2013:17:356

2 Wolfe F, Ross K, Anderson J, et al. The prevalence and characteristics of fibromyalgia in the general population. Arthritis Rheum 1995;38:19-28.

3 Choy E, Perrot S, Leon T, et al. A patient survey of the impact of fibromyalgia and the journey to diagnosis. BMC Health Serv Res 2010;10:102.

4 Boonen $A$, van den Heuvel $R$, van Tubergen $A$, et al. Large differences in cost of illness and wellbeing between patients with fibromyalgia, chronic low back pain, or ankylosing spondylitis. Ann Rheum Dis 2005;64:396-402.

5 HäuserW, Zimmer C, et al. [What are the key symptoms of fibromyalgia? Results of a survey of the German Fibromyalgia Association]. Schmerz 2008;22:176-83.

6 Fietta P, Manganelli P. Fibromyalgia and psychiatric disorders. Acta Biomed 2007;78:88-95

7 Carville SF, Arendt-Nielsen L, Bliddal $H$, et al. EULAR evidence-based recommendations for the management of fibromyalgia syndrome. Ann Rheum Dis 2008;67:536-41.

8 Shea BJ, Grimshaw JM, Wells GA, et al. Development of AMSTAR: a measurement tool to assess the methodological quality of systematic reviews. BMC Med Res Methodol 2007;7:10.

9 Abeles M, Solitar BM, Pillinger MH, et al. Update on fibromyalgia therapy. Am J Med 2008:121:555-61.

10 Guyatt G, Oxman AD, Akl EA, et al. GRADE guidelines: 1. Introduction—GRADE evidence profiles and summary of findings tables. I Clin Epidemiol 2011;64:383-94.

11 Andrews JC, Schünemann HJ, Oxman AD, et al. GRADE guidelines: 15. Going from evidence to recommendation - determinants of a recommendation's direction and strength. J Clin Epidemiol 2013;66:726-35.

12 Häuser W, Petzke F, Üçeyler N, et al. Comparative efficacy and acceptability of amitriptyline, duloxetine and milnacipran in fibromyalgia syndrome: a systematic review with meta-analysis. Rheumatology 2011;50:532-43.
13 Nishishinya B, Urrútia $G$, Walitt B, et al. Amitriptyline in the treatment of fibromyalgia: a systematic review of its efficacy. Rheumatology (Oxford) 2008:47:1741-6.

14 Üçeyler N, Häuser W, Sommer C. A systematic review on the effectiveness of treatment with antidepressants in fibromyalgia syndrome. Arthritis Care Res 2008;59:1279-98.

15 Moore RA, Derry S, Aldington D, et al. Amitriptyline for neuropathic pain and fibromyalgia in adults. Cochrane Database Syst Rev 2012;(12):CD008242.

16 Perrot S, Russell IJ. More ubiquitous effects from non-pharmacologic than from pharmacologic treatments for fibromyalgia syndrome: a meta-analysis examining six core symptoms. Eur J Pain 2014;18:1067-80.

17 Häuser W, Bernardy K, Üçeyler N, et al. Treatment of fibromyalgia syndrome with gabapentin and pregabalin-a meta-analysis of randomized controlled trials. Pain 2009;145:69-81.

18 Moore RA, Straube S, Wiffen PJ, et al. Pregabalin for acute and chronic pain in adults. Cochrane Database Syst Rev 2009;(3):CD007076.

19 Häuser W, Petzke F, Sommer C. Comparative efficacy and harms of duloxetine, milnacipran, and pregabalin in fibromyalgia syndrome. J Pain 2010;11:505-21.

20 Tzellos TG, Toulis KA, Goulis DG, et al. Gabapentin and pregabalin in the treatment of fibromyalgia: a systematic review and a meta-analysis. I Clin Pharm Ther 2010;35:639-56.

21 Choy E, Marshall D, Gabriel ZL, et al. A systematic review and mixed treatment comparison of the efficacy of pharmacological treatments for fibromyalgia. Semin Arthritis Rheum 2011:41:335-45.

22 Roskell NS, Beard SM, Zhao Y, et al. A meta-analysis of pain response in the treatment of fibromyalgia. Pain Pract 2011;11:516-27.

23 Siler $\mathrm{AC}$, Gardner $\mathrm{H}$, Yanit $\mathrm{K}$, et al. Systematic review of the comparative effectiveness of antiepileptic drugs for fibromyalgia. J Pain 2011;12:407-15.

24 Üçeyler N, Sommer C, Walitt B, et al. Anticonvulsants for fibromyalgia. Cochrane Database Syst Rev 2013;(10):CD010782.

25 Tofferi JK, Jackson JL, O'Malley PG. Treatment of fibromyalgia with cyclobenzaprine: a meta-analysis. Arthritis Care Res 2004;51:9-13.

26 Häuser W, Bernardy K, Üçeyler N, et al. Treatment of fibromyalgia syndrome with antidepressants: a meta-analysis. JAMA 2009;301:198-209.

27 Tort S, Urrútia G, Nishishinya MB, et al. Monoamine oxidase inhibitors (MAOls) for fibromyalgia syndrome. Cochrane Database Syst Rev 2012;(4):CD009807.

28 Sultan A, Gaskell H, Derry S, et al. Duloxetine for painful diabetic neuropathy and fibromyalgia pain: systematic review of randomised trials. BMC Neurol 2008;8:29.

29 Lunn MP, Hughes RA, Wiffen PJ. Duloxetine for treating painful neuropathy or chronic pain. Cochrane Database Syst Rev 2009;(4):CD007115.

30 Häuser W, Urrútia G, Tort S, et al. Serotonin and noradrenaline reuptake inhibitors (SNRIs) for fibromyalgia syndrome. Cochrane Database Syst Rev 2013;(1):CD010292.

31 Ormseth MJ, Eyler AE, Hammonds $\mathrm{CL}$, et al. Milnacipran for the management of fibromyalgia syndrome. J Pain Res 2010;3:15-24.

32 Lunn MP, Hughes RA, Wiffen PJ. Duloxetine for treating painful neuropathy, chronic pain or fibromyalgia. Cochrane Database Syst Rev 2014;(1):CD007115.

33 Derry S, Gill D, Phillips T, et al. Milnacipran for neuropathic pain and fibromyalgia in adults. Cochrane Database Syst Rev 2012;(3):CD008244.

34 Jung AC, Staiger T, Sullivan M. The efficacy of selective serotonin reuptake inhibitors for the management of chronic pain. J Gen Intern Med 1997;12:384-9.

35 Arnold LM, Keck PE, Welge JA. Antidepressant treatment of fibromyalgia. A meta-analysis and review. Psychosomatics 2000;41:104-13.

36 Häuser W, Wolfe F, Tölle $T$, et al. The role of antidepressants in the management of fibromyalgia syndrome. Central Nervous System Drugs 2012;26:297-307.

37 Bednar ML, Soroczynski AC, Groman MJ, et al. Effectiveness of land-based and aquatic-based exercises for improving the health status of individuals with fibromyalgia: a systematic review. J Aquat Phys Ther 2012;19:26-35.

38 Brosseau L, Wells GA, Tugwell P, et al. Ottawa Panel evidence-based clinical practice guidelines for aerobic fitness exercises in the management of fibromyalgia: part 1. Phys Ther 2008;88:857-71.

39 Brosseau L, Wells GA, Tugwell $P$, et al. Ottawa Panel evidence-based clinical practice guidelines for strengthening exercises in the management of fibromyalgia: part 2. Phys Ther 2008;88:873-86.

40 Busch AJ, Schachter CL, Peloso PM. Fibromyalgia and exercise training: a systematic review of randomized clinical trials. Phys Ther Rev 2001;6:287-306.

41 Busch AJ, Barber KA, Overend TJ, et al. Exercise for treating fibromyalgia syndrome. Cochrane Database Syst Rev 2008;(4):CD003786.

42 Busch AJ, Webber SC, Richards RS. Resistance exercise training for fibromyalgia. Cochrane Database Syst Rev 2013;(12):CD010884.

43 Cazzola M, Atzeni F, Salaffi F, et al. Which kind of exercise is best in fibromyalgia therapeutic programmes? A practical review. Clin Exp Rheumatol 2009;28(Suppl 63):S117-24.

44 Häuser W, Klose P, Langhorst J, et al. Efficacy of different types of aerobic exercise in fibromyalgia syndrome: a systematic review and meta-analysis of randomised controlled trials. Arthritis Res Ther 2010;12:R79.

45 Kelley GA, Kelley KS, Hootman JM, et al. Exercise and global well-being in community-dwelling adults with fibromyalgia: a systematic review with meta-analysis. BMC Public Health 2010;10:198. 
46 Kelley GA, Kelley KS, Jones DL. Efficacy and effectiveness of exercise on tender points in adults with fibromyalgia: a meta-analysis of randomized controlled trials. Arthritis 2011;2011:125485.

47 Lima TB, Dias JM, Mazuquin BF, et al. The effectiveness of aquatic physical therapy in the treatment of fibromyalgia: a systematic review with meta-analysis. Clin Rehabil 2013;27:892-908.

48 Nüesch E, Häuser W, Bernardy K, et al. Comparative efficacy of pharmacological and non-pharmacological interventions in fibromyalgia syndrome: network meta-analysis. Ann Rheum Dis 2013;72:955-62.

49 Perraton L, Machotka Z, Kumar S. Components of effective randomized controlled trials of hydrotherapy programs for fibromyalgia syndrome: a systematic review. J Pain Res 2009:2:165-73.

50 Ramel J, Bannuru R, Griffith M, et al. Exercise for fibromyalgia pain: a meta-analysis of randomized controlled trials. Curr Rheumatol Rev 2009;5:188-93.

51 Reimers N, Reimers CD. Exercise for lower back pain, hip and knee osteoarthritis, and fibromyalgia: effects on pain-a literature review. Aktuelle Rheumatologie 2012;37:174-88

52 Sim J, Adams N. Systematic review of randomized controlled trials of nonpharmacological interventions for fibromyalgia. Clin J Pain 2002;18:324-36.

53 Thomas EN, Blotman F. Aerobic exercise in fibromyalgia: a practical review. Rheumatol Int 2010:30:1143-50.

54 van Koulil S, Effting M, Kraaimaat FW, et al. Cognitive-behavioural therapies and exercise programmes for patients with fibromyalgia: state of the art and future directions. Ann Rheum Dis 2007;66:571-81.

55 Mansi S, Milosavljevic S, Baxter GD, et al. A systematic review of studies using pedometers as an intervention for musculoskeletal diseases. BMC Musculoskelet Disord 2014;15:231.

56 Bidonde J, Busch AJ, Webber SC, et al. Aquatic exercise training for fibromyalgia. Cochrane Database Syst Rev 2014;(10):CD011336.

57 Bernardy K, Füber N, Köllner V, et al. Efficacy of cognitive-behavioral therapies in fibromyalgia syndrome-a systematic review and metaanalysis of randomized controlled trials. J Rheumatol 2010;37:1991-2005.

58 Bernardy K, Klose P, Busch AJ, et al. Cognitive behavioural therapies for fibromyalgia. Cochrane Database Syst Rev 2013;(9):CD009796.

59 Karjalainen KA, Malmivaara A, van Tulder MW, et al. Multidisciplinary rehabilitation for fibromyalgia and musculoskeletal pain in working age adults. Cochrane Database Syst Rev 1999;(3):CD001984.

60 Häuser W, Bernardy K, Arnold B, et al. Efficacy of multicomponent treatment in fibromyalgia syndrome: a meta-analysis of randomized controlled clinical trials. Arthritis Care Res 2009;61:216-24.

61 Scascighini L, Toma V, Dober-Spielmann S, et al. Multidisciplinary treatment for chronic pain: a systematic review of interventions and outcomes. Rheumatology (Oxford) 2008:47:670-8

62 Kalichman L. Massage therapy for fibromyalgia symptoms. Rheumatol Int 2010;30:1151-7.

63 Li YH, Wang FY, Feng CQ, et al. Massage therapy for fibromyalgia: a systematic review and meta-analysis of randomized controlled trials. PLOS ONE 2014;9:e89304.

64 Tsao JC. Effectiveness of massage therapy for chronic, non-malignant pain: a review. Evid Based Complement Alternat Med 2007;4:165-79.

65 Yuan SLK, Matsutani LA, Marques AP. Effectiveness of different styles of massage therapy in fibromyalgia: a systematic review and meta-analysis. Man Ther 2015:20:257-64.

66 Courtois I, Cools F, Calsius J. Effectiveness of body awareness interventions in fibromyalgia and chronic fatigue syndrome: a systematic review and meta-analysis. J Bodyw Mov Ther 2015;19:35-56.

67 Berman BM, Ezzo J, Hadhazy V, et al. Is acupuncture effective in the treatment of fibromyalgia? J Fam Pract 1999;48:213-18

68 Cao H, Li X, Han M, et al. Acupoint stimulation for fibromyalgia: a systematic review of randomized controlled trials. Evid Based Complement Alternat Med 2013;2013:362831.

69 Daya S. The efficacy of acupuncture in the treatment of fibromyalgia syndrome. Acupunct Assoc Charter Physiother 2007;3:35-46.

70 Deare JC, Zheng Z, Xue CC. Acupuncture for treating fibromyalgia. Cochrane Database Syst Rev 2013;(5):CD007070.

71 Langhorst J, Klose P, Musial F, et al. Efficacy of acupuncture in fibromyalgia syndrome-a systematic review with a meta-analysis of controlled clinical trials. Rheumatology (Oxford) 2010;49:778-88.

72 Martin-Sanchez E, Torralba E, Díaz-Domínguez E, et al. Efficacy of acupuncture fo the treatment of fibromyalgia: systematic review and meta-analysis of randomized trials. Open Rheumatol J 2009;3:25-9.

73 Mayhew E, Ernst E. Acupuncture for fibromyalgia - a systematic review of randomized clinical trials. Rheumatology (Oxford) 2007;46:801-4.

74 Yang $B, Y i$ G, Hong $W$, et al. Efficacy of acupuncture on fibromyalgia syndrome: a meta-analysis. J Tradit Chin Med 2014;34:381-91.

75 McVeigh JG, McGaughey H, Hall M, et al. The effectiveness of hydrotherapy in the management of fibromyalgia syndrome: a systematic review. Rheumatol Int 2008:29:119-30.
76 Langhorst J, Musial F, Klose P, et al. Efficacy of hydrotherapy in fibromyalgia syndrome-a meta-analysis of randomized controlled clinical trials. Rheumatology (Oxford) 2009;48:1155-9.

77 Naumann J, Sadaghiani C. Therapeutic benefit of balneotherapy and hydrotherapy in the management of fibromyalgia syndrome: a qualitative systematic review and meta-analysis of randomized controlled trials. Arthritis Res Ther 2014;16:R141.

78 Chan CL, Wang CW, Ho RT, et al. Qigong exercise for the treatment of fibromyalgia: a systematic review of randomized controlled trials. J Altern Complement Med 2012;18:641-6.

79 Cramer $\mathrm{H}$, Lauche R, Langhorst J, et al. Yoga for rheumatic diseases: a systematic review. Rheumatology (Oxford) 2013;52:2025-30.

80 Langhorst J, Klose P, Dobos GJ, et al. Efficacy and safety of meditative movement therapies in fibromyalgia syndrome: a systematic review and meta-analysis of randomized controlled trials. Rheumatol Int 2013;33:193-207

81 Lauche R, Cramer H, Häuser W, et al. A systematic review and meta-analysis of qigong for the fibromyalgia syndrome. Evid Based Complement Alternat Med 2013:2013:635182.

82 Peng PW. Tai Chi and chronic pain. Reg Anesth Pain Med 2012;37:372-82.

83 Hadhazy VA, Ezzo J, Creamer $P$, et al. Mind-body therapies for the treatment of fibromyalgia. A systematic review. J Rheumatol 2000;27:2911-18.

84 Lauche $\mathrm{R}$, Cramer H, Dobos $\mathrm{G}$, et al. A systematic review and meta-analysis of mindfulness-based stress reduction for the fibromyalgia syndrome. J Psychosom Res 2013:75:500-10.

85 Niazi AK, Niazi SK. Mindfulness-based stress reduction: a non-pharmacological approach for chronic illnesses. N Am J Med Sci 2011;3:20-3.

86 Lakhan SE, Schofield KL. Mindfulness-based therapies in the treatment of somatization disorders: a systematic review and meta-analysis. PLOS ONE 2013;8: e71834.

87 Lee C, Crawford C, Hickey A. Mind-body therapies for the self-management of chronic pain symptoms. Pain Med 2014;15(Suppl 1):S21-39.

88 Ernst E. Chiropractic manipulation for non-spinal pain-a systematic review. N Z Med J 2003:116:U539.

89 Ernst E. Chiropractic treatment for fibromyalgia: a systematic review. Clin Rheumatol 2009;28:1175-8.

90 Schneider $\mathrm{M}$, Vernon $\mathrm{H}, \mathrm{Ko} \mathrm{G}$, et al. Chiropractic management of fibromyalgia syndrome: a systematic review of the literature. J Manipulative Physiol Ther 2009;32:25-40.

91 Bernardy K, Füber N, Klose $\mathrm{P}$, et al. Efficacy of hypnosis/guided imagery in fibromyalgia syndrome-a systematic review and meta-analysis of controlled trials. BMC Musculoskelet Disord 2011;12:133.

92 Glombiewski JA, Bernardy K, Häuser W. Efficacy of EMG- and EEG-biofeedback in fibromyalgia syndrome: a meta-analysis and a systematic review of randomized controlled trials. Evid Based Complement Alternat Med 2013;2013:962741.

93 De Silva V, El-Metwally A, Ernst E, et al. Evidence for the efficacy of complementary and alternative medicines in the management of fibromyalgia: a systematic review. Rheumatology (Oxford) 2010;49:1063-8.

94 de Souza Nascimento S, Desantana JM, Nampo FK, et al. Efficacy and safety of medicinal plants or related natural products for fibromyalgia: a systematic review. Evid Based Complement Alternat Med 2013;2013:149468.

95 Posadzki P, Ernst E. Guided imagery for musculoskeletal pain: a systematic review. Clin J Pain 2011:27:648-53.

96 Meeus M, Nijs J, Vanderheiden T, et al. The effect of relaxation therapy on autonomic functioning, symptoms and daily functioning, in patients with chronic fatigue syndrome or fibromyalgia: a systematic review. Clin Rehabil 2015;29:221-33.

97 Perry $R$, Terry R, Ernst E. A systematic review of homoeopathy for the treatment of fibromyalgia. Clin Rheumatol 2010;29:457-64.

98 Boehm K, Raak C, Cramer H, et al. Homeopathy in the treatment of fibromyalgia - a comprehensive literature-review and meta-analysis. Complement Ther Med 2014;22:731-42.

99 Ricci NA, Dias CN, Driusso P. The use of electrothermal and phototherapeutic methods for the treatment of fibromyalgia syndrome: a systematic review. Rev Bras Fisioter 2010;14:1-9.

100 Tenti S, Manica P, Galeazzi M, et al. Phytothermotherapy in fibromyalgia and osteoarthritis: between tradition and modern medicine. Eur J Integr Med 2013:5:248-53.

101 Eccles NK. A critical review of randomized controlled trials of static magnets for pain relief. J Altern Complement Med 2005;11:495-509.

102 Marlow NM, Bonilha HS, Short EB. Efficacy of transcranial direct current stimulation and repetitive transcranial magnetic stimulation for treating fibromyalgia syndrome: a systematic review. Pain Pract 2013;13:131-45.

103 Crawford C, Lee C, Bingham J. Sensory art therapies for the self-management of chronic pain symptoms. Pain Med 2014;15(Suppl 1):S66-75.

104 Moore RA, Wiffen PJ, Derry S. Gabapentin for chronic neuropathic pain and fibromyalgia in adults. Cochrane Database Syst Rev 2014;(4):CD007938.

105 Ablin J, Fitzcharles MA, Buskila D, et al. Treatment of fibromyalgia syndrome: recommendations of recent evidence-based interdisciplinary guidelines with special emphasis on complementary and alternative therapies. Evid Based Complement Alternat Med 2013:2013:485272. 